\title{
Supporting Visual Literacy in Nursing
}

\author{
Jacqueline Fleming \\ Indiana University, USA \\ Amy Minix \\ Indiana University, USA
}

\begin{abstract}
COVID-19 impacted in person learning, particularly for the health sciences. Nursing students learn valuable clinical skills in simulation labs on campus. When one university campus stopped in person instruction during the 2020 spring semester, two librarians worked together to identify resources to support a nursing course that quickly switched to remote learning. These resources ranged from library licensed content to free virtual reality simulations. In order to identify materials, the librarians first defined visual literacy within nursing, as well as met with various constituents to understand curriculum goals and needs. Making connections with both the faculty and the curriculum was the impetus for examining similarities between the Association of College and Research Libraries Visual Literacy Competency Standards and the American Association of Colleges of Nursing Clinical Resources Essentials for Baccalaureate Nursing Education. Both librarians are eager to continue working on strategically and systematically incorporating visual literacy library instruction into the nursing curriculum.
\end{abstract}

Keywords: Visual Literacy, Nursing Education, Health Sciences, Virtual Reality

\section{Introduction}

In March 2020, COVID-19 drastically changed educational practices. Face-to-face instruction quickly transitioned into emergency remote teaching; resources for on-campus learning shut down and instructors were left scrambling to adjust their instruction plans to an online environment for the rest of the semester. This challenging time for instructors created an opportunity for librarians to help faculty transition to online teaching. Specifically, this paper discusses a collaboration between librarians and the School of Nursing at Indiana University.

At Indiana University, the School of Nursing incorporates multiple hands-on learning activities and in-person simulations. These are done through the use of the school's Inter-Professional Simulation Center and the Nursing Learning Center ${ }^{1}$. However, both of these learning facilities closed in March 2020 with the rest of the campus. This eliminated many learning and assessment opportunities of clinical skills that nursing students and professors rely on. The only option for professors in the School of Nursing was to adapt simulation learning to an online environment only. This was difficult for nursing professors and it was a situation that they were not prepared for.

Jackie Fleming, the Visual Literacy Librarian, and Amy Minix, the Neuro-Health Sciences Librarian, saw this uncertain time at their institution as a way to help incorporate visual literacy into the nursing curriculum and assist professors by finding digital simulation alternatives to the normally in-person simulations. Both librarians collaborated to address the challenges and opportunities of shifting a physical simulation lab learning into an online environment. These difficulties included understanding how visual literacy is defined in nursing, as well as learning the visual literacy and discipline-specific objectives and skills that are taught in simulation labs. Fleming and Minix also needed to understand the scope of virtual reality (VR), augmented reality, online videos, and other tools to aid teaching and learning in order to best support instruction that would typically take place in a simulation lab. Both librarians saw this as an opportunity to identify and amplify relevant library and open resources, as well as identifying visual literacy connections in the curriculum.

The initial step in addressing these challenges was to conduct a literature review in order to understand the characteristics of an effective nurse, simulation learning in nursing education, and the current role that visual literacy plays in nursing education (see Figure 1). After conducting the literature review, both librarians felt that using a basic framework for introducing visual literacy into the School of Nursing would 
be beneficial. Fleming and Minix created this framework by mapping the ACRL Visual Literacy Competency Standards 2011 (ACRL Standards) to the American Association of Colleges of Nursing Clinical Resources Essentials for Baccalaureate Nursing Education 2008 (AACN Essentials). From this mapping exercise, the authors were able to write a definition of visual literacy within the context of nursing education and start the process of creating discipline specific learning objectives that incorporate visual literacy. The authors also reviewed current and free virtual simulation resources, as well as resources provided through their institution. They then created a spreadsheet with this information to distribute to teaching contacts within the School of Nursing.

\section{Figure 1}

Infographic of the process for implementing visual literacy in a nursing curriculum

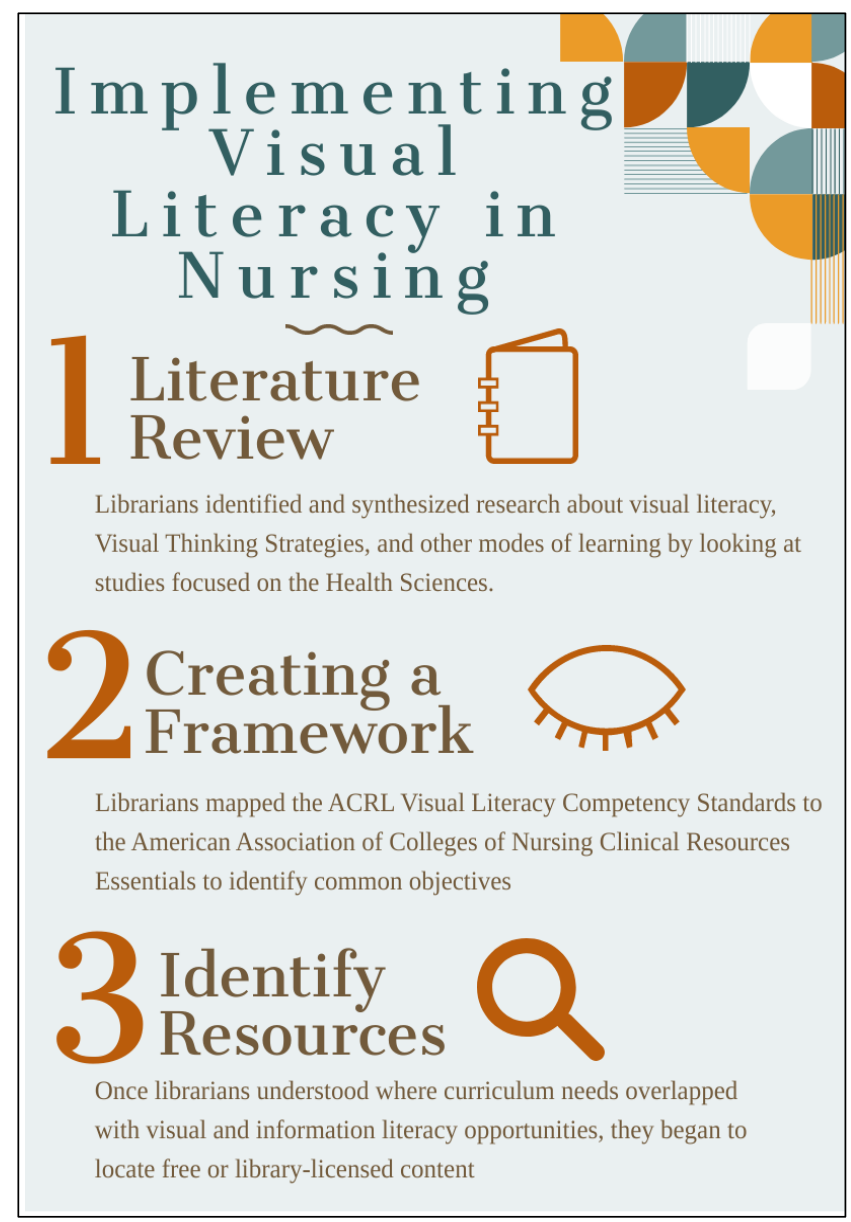

When the librarians presented at the International Visual Literacy Association's virtual conference in September 2020, they described their ideas and the initial steps. The purpose of this article is to give a more thorough description of this project, explain why visual literacy is a skill for nursing students, and describe the next steps that the authors hope to take.

\section{Literature Review:}

A majority of the literature that discusses visual literacy in nursing education agrees that being able to observe visual stimulus is an important skill for all medical professionals. One common method for teaching observation skills to medical students has been visual thinking exercises. Visual thinking strategies method is defined as "a method used to focus visual observations to enhance critical thinking and language skills" 
(Jasani et al., 2013, p. e1327). This method of teaching critical thinking and close-looking through the observation of artwork comes from the research of Abigail Housen. Housen defines Visual Thinking Strategies as a student-centered curriculum where teachers "pose open-ended questions, encourage the group members to think out loud, encourage every participant to speak, and allow repeated opportunity to share what is seen" (2002). Abigail Housen expanded her research by co-founding the organization Visual Thinking Strategies (VTS) ${ }^{2}$ with Philip Yenawine. This organization trains educators from a variety of backgrounds to become certified members of the VTS community. The training sessions led by VTS facilitators can happen in an art museum or any educational setting. There have been many partnerships established between nursing schools and their institution's art museums to help increase the observation training of their nursing students ${ }^{3}$.

VTS has been embraced in a variety of ways by nursing educators. Numerous case studies discuss situations where visual thinking helps nursing students grow their observational skills (Jasani, 2013; Moorman, 2015; Moorman et al., 2017; Shapiro et al. 2006). During sessions, nursing students look at a work of art while VTS facilitators ask them three questions: What is going on in this picture? What do you see that makes you say that? What more can you find? (Moorman, 2015, p. 750). After the first question is asked and answered, the facilitator repeats back to the students their answer. This is done for clarification and for the students to get more practice with visual communication. The last question is posed to the group of students so they can work together to communicate what other details and characteristics of the artwork they can find as a group (Moorman, 2015, p. 750).

Research shows that VTS training sessions are generally effective ways of increasing nursing students' observational skills (Grossman et al., 2013). In her article exploring the opinion of nursing students who have gone through VTS training, Moorman (2015) discovered that two main themes were emphasized in the participating students' responses: feeling safe in learning and thinking differently (p.751). In reference to feeling safe in learning, Moorman's study recognized that nursing students appreciated that there were no right or wrong answers in giving visual observations during the VTS session (p.751). The students felt comfortable participating in front of their peers because there was no fear of being labeled as wrong. After attending two VTS sessions, the students noticed an increase in their attention to detail when observing patients and a positive impact on their ability to communicate visually with their peers (p.753). It is important to note that it took merely two VTS training sessions to increase the nursing student's ability to communicate and observe visually.

There are a number of articles discussing the recent popularity of online learning simulations and blended learning modules for nursing programs. Choi et al. (2020) defines virtual simulations in nursing education as the use of "interactive technology providing a realistic clinical situation in a virtual world where students can engage in decision making with realistic changes within the situation as the simulation unfolds" (p.104623). These simulations are used as a way to "put" nursing students in a semi-real situation they may find themselves in their future careers. It is important to give the students practice in these high-pressure situations so they can grow their ability to make life and death choices when needed. For this purpose, virtual simulations are used to assess clinical competency and emotion recognition of nursing students during the simulations (Mano et al., 2019).

\section{Defining Visual Literacy in the Context of Nursing Education}

In the scope of their literature review, the authors did not find a definition of visual literacy that would work well with the intent of their project and incorporated the structure of the ACRL Standards. Because of this challenge, the authors decided to write their own definition of visual literacy within the context of nursing. This definition uses the structure of the ACRL Standards visual literacy definition and was heavily informed by the literature review mapping exercise with the ACRL Standards and AACN Essentials. The authors defined visual literacy as, "a skill set that allows nursing students to be astute observers in their work and daily lives. A visually literate nursing student thinks critically about visual stimulus in their profession, assesses physical symptoms with accuracy, and develops a care plan for their patients with the long term goal in mind"4.

\section{Mapping the Essentials to the ACRL Standards}

To begin this process, the authors first needed to understand and identify the overlap between the nursing 
accreditation concepts and the visual literacy standards. The authors' institution's School of Nursing uses the American Association of Colleges of Nursing (AACN) Baccalaureate Essentials (American Association of Colleges of Nursing [AACN], 2008) as their framework for nursing curricula; the AACN Essentials provide specific concepts that nursing students will become proficient in once they complete their baccalaureate education. The Association of College and Research Libraries (ACRL) established the "Visual Literacy Competency Standards for Higher Education" (2011) to guide visual literacy within interdisciplinary higher education. The authors' compared the ACRL Standards to the AACN Essentials in order to map similarities between the two measures and identify possible opportunities for visual and information literacy in nursing.

Matching concepts geared toward nursing proficiency to the visual literacy competency standards was not an exact one-to-one translation. However, there are common goals shared between the two measures, and identifying them helped frame how visual literacy could be addressed in nursing at the authors' specific institution. Additionally, it is helpful to know which visual skills students are working on when identifying potential coursework material.

The authors first looked at the first standard of the ACRL Standards, which states that the visually literate student, "determines the nature and extent of the visual materials needed" (ACRL Visual Literacy Competency Standards, 2011). Each standard has performance indicators as well as learning outcomes, which provides general information regardless of the course or discipline. For the purpose of this exercise, the authors identified relevant performance indicators; the learning outcomes helped narrow specific skills that would translate through the AACN Essentials. The performance indicators selected from standard one express that the visually literate student being able to: "identify a variety of image sources, materials, and types" and "articulate ways images can be used to communicate data and information (e.g., charts, graphs, maps, diagrams, models, renderings, elevations)" (ACRL 2011).

The next step involved identifying specific examples or skills within AACN Essentials based on the broad performance indicators provided by the ACRL Standards. The fourth nursing essential, information management and application of patient care technology, aligned well with visual competency standard one. The fourth concept in the AACN Essentials (2008) states that:

Graduates must have basic competence in technical skills, which includes the use of computers, as well as the application of patient care technologies such as monitors, data gathering devices, and other technological supports for patient care interventions. In addition, baccalaureate graduates must have competence in the use of information technology systems, including decision -support systems, to gather evidence to guide practice. Specific introductory level nursing informatics competencies include the ability to use selected applications in a comfortable and knowledgeable way. (p. 17)

The AACN Essentials also include performance indicators that provide context. These indicators state that nursing students will be able to: "evaluate data from all relevant sources, including technology, to inform the delivery of care" and "demonstrate skills in using patient care technologies, information systems, and communication devices that support safe nursing practice" (e.g., retrieval information systems, including access, evaluation of data, and application of relevant data to patient care) (AACN, 2008, p. 18).

The shared goals for both ACRL Standard one and the fourth essential is using visual information as evidence. Visual information in the nursing field can come in many forms, including charts, graphs, and other data. Nurses use these data to make informed decisions by understanding the technology and tools in their field. Addressing these common factors between the Essentials and the ACRL Standards may help name and scaffold these skills in a meaningful way with the help of librarians (see Table 1).

The second set of ACRL Standard competencies the authors examined was standard three, which defines the visually literate student being able to, "interpret and analyze the meanings of images and visual media" (ACRL Visual Literacy Competency Standards, 2011). The performance indicators selected from standard three express the visually literate student being able to: "identify information relevant to an image's meaning; examines the relationships of images to each other and uses related images to inform interpretation; and recognizes when more information about an image is needed, develops questions for further research, and conducts research as appropriate." 
Table 1

Mapping ACRL Standard One to AACN Essential IV

\section{ACRL Standard One-The visually literate student \\ determines the nature and extent of the visual \\ materials needed.}

\section{Performance Indicators:}

- identifies a variety of image sources, materials, and types.

-Articulates ways images can be used to communicate data and information (e.g., charts, graphs, maps, diagrams, models, renderings, elevations).
Essential IV-Information Management and

Application of Patient Care Technology

Performance Indicators:

-Evaluate data from all relevant sources, including technology to inform the delivery of care.

Note: The similarities between the ACRL Standard One and the AACN Essential IV are in bolded text.

Coincidentally, the third ACRL Standard indicators aligned with the third AACN Essential, focuses on the scholarship of evidence-based practice. This essential "provides a basic understanding of how evidence is developed, including the research process, clinical judgement, interprofessional perspectives, and patient preference as applied to practice" (AACN, 2008, p.16). The performance indicators state that nursing students should be able to: "integrate evidence, clinical judgement, interprofessional perspectives, and patient preferences in planning, implementing, and evaluating outcomes of care" and "collaborate in the collection, documentation, and dissemination of evidence" (e.g., principles and models of evidence-based practice and nurse sensitive quality indicators performance measures) (AACN, 2008, p. 16).

The alignment between ACRL Standard three and the third essential focus on the idea that patients are the images themselves. This notion that patients are the images being analyzed and interpreted pushes the definition of what an "image" is. However, looking at visual cues to help determine the next point of care in conjunction with visual evidence (e.g., gathering additional information from visual data or determining when more information is needed) are critical skills nursing students should master (see Table 2).

The authors would like to expand and explore how targeted library instruction can improve specific nursing skills in their practice through a visual and information literacy lens. The goal of this exercise was to identify and name common areas as a way to start a conversation. The authors recognize this approach will have to be performed again in a more targeted, minute way at both the curriculum and course levels.

Table 2

Mapping ACRL Standard Three to AACN Essential III

ACRL Standard Three- The visually literate student

interprets and analyzes the meanings of images

and visual media.

- Identifies information relevant to an image's meaning.

-Examines the relationships of images to each other and uses related images to inform interpretation. -Recognizes when more information is needed, develops questions for further research, and conducts additional research as appropriate.
Essential III-Scholarship of Evidence Based-Practice

-Integrate evidence, clinical judgement, interprofessional perspectives, and patient preferences in planning, implementing, and evaluating outcomes of care.

-Collaborate in the collection, documentation, and dissemination of evidence.

Note: The Similarities between ACRL Standard Three to AACN Essential III are in bolded text. 


\section{Curriculum Needs \& Locating Resources}

COVID-19 and the switch from physical learning into an online environment was the catalyst that brought this project into fruition. Fleming began reaching out to subject-area librarians shortly after she was hired in order to discuss and explore what visual literacy looks like throughout a variety of disciplines. Minix recently acquired nursing liaison librarian responsibilities and was working on understanding what the curriculum needs of the nursing school are and how library instruction and services could support them. The timing, focus, and newness to their respective areas provided space to explore this topic.

The librarians began by meeting with the simulation lab coordinator, Sally Gindling, to learn about clinical simulation at the campus. Gindling shared specific examples that demonstrated how attentive students must be to patients and how dynamic that can be. For example, the coordinator might be emulating a homeless patient or a five-year old child. Visual elements could include all of the person's belongings in the corner of the simulation room for the former patient example or something as simple as using a teddy bear as a prop in the latter; these details help create a narrative and environment that nursing students will experience in their jobs. Thus conversations about visual literacy within nursing began and the authors decided to learn more.

Per Gindling's recommendation, the authors met with a faculty member whose courses centered on the simulation lab. Dr. Roxie Barnes is an assistant professor at Indiana University, and she met with the authors during the summer of 2020 to discuss her course and the challenges she faced switching from in person instruction to online. Dr. Barnes discussed how students were not able to participate in physical simulations in the Spring 2020 semester due to COVID-19. Instead, she pulled videos from past simulation labs and used those as discussion starters, where students could share what they thought went well and what they would've done differently.

One of the challenges Dr. Barnes shared was the prohibitive costs of platforms that offered virtual or augmented simulation experiences. Although there are a number of tools out there, budget cuts prevented many departments and schools from switching to these technologies in light of COVID-19. The authors saw this as an opportunity to help define what visual literacy is within the scope of nursing education, which would then help identify library or Open Access (OA) resources to support this course.

Minix began by using a course mapping spreadsheet ${ }^{5}$ she had used on a previous Open Education Resource project. The spreadsheet, provided by librarian Willa Tavernier in the Scholarly Communications department within IU Libraries, organized important course concepts based on the current assigned textbook. Next, Minix identified library licensed platforms that housed visual content, which included Films on Demand: Nursing Collection, Nursing Education in Video, and the Journal of Visualized Experiments (JoVE). In addition, she also looked for materials that were Open Access or Open Education Resources through resources provided by the Scholarly Communications Librarian Sarah Hare, also at Indiana University Libraries. The National League for Nursing (NLN) released a document that provided virtual simulation options for undergraduate nursing students (American Association of Colleges of Nursing, 2008). The spreadsheet helped organize and facilitate searching throughout the various information systems and provided Dr. Barnes with an accessible document to work through and ultimately decide which resources would suit her course needs best (see Figure 2).

\section{Process and Next Steps:}

The authors are currently working on forming learning outcomes nursing professors can incorporate into their own instruction practices. These learning outcomes will emphasize visual literacy skills within the context of nursing education. Through the literature review, the authors were able to identify four general skills that nursing students need to have in order to be successful. Those four areas are visual communication, observation skills, critical thinking and data literacy. These four areas were used to categorize the ACRL Standards and the AACN Essentials (see Table 3). The purpose this exercise was to match like-terminology within both sets of competencies. This enables the authors to identify specific skills that nursing students need within the four categories identified in the literature review. 


\section{Figure 2}

Sample of library-licensed and open access content mapped to the curriculum

\begin{tabular}{|c|c|c|c|c|c|c|}
\hline Resource & $\begin{array}{l}\text { Current } \\
\text { Textbook: } \\
\text { Understanding } \\
\text { Essentials of } \\
\text { Critical Care } \\
\text { Perrin and } \\
\text { MaCleod }\end{array}$ & Key Concepts: & $\begin{array}{l}\text { Library Owns: } \\
\text { Films on } \\
\text { Demand: } \\
\text { Nursing } \\
\text { Collection }\end{array}$ & $\begin{array}{l}\text { OER } \\
\text { Resources }\end{array}$ & $\begin{array}{l}\text { Library Owns: } \\
\text { JoVe }\end{array}$ & $\begin{array}{l}\text { Library Owns: } \\
\text { Nursing } \\
\text { Education in } \\
\text { Video }\end{array}$ \\
\hline Chapter 10 & $\begin{array}{l}\text { care of the patient } \\
\text { experiencing an } \\
\text { intracranial } \\
\text { dysfunction }\end{array}$ & $\begin{array}{l}\text { intracranial pressure, } \\
\text { assessment of patient } \\
\text { with a potential for } \\
\text { increased intracranial } \\
\text { pressure, primary cause } \\
\text { of increased intracranial } \\
\text { Pressure: TBI, Primary } \\
\text { cause of increased } \\
\text { intracranial pressure: } \\
\text { Meningitis and seizures }\end{array}$ & $\begin{array}{l}\text { Intracranial } \\
\text { pressure } \\
\text { (https://fod-info } \\
\text { base-com.proxy } \\
\text { iub.uits.iu.edu/p } \\
\text { Search.aspx? } \\
\text { bc=0\&rd=a\&q=i } \\
\text { ntracranial) }\end{array}$ & N/A & $\begin{array}{l}\text { Intracranial } \\
\text { (https://video-al } \\
\text { exanderstreet-c } \\
\text { om.proxyiub.uit } \\
\text { s.iu.edu/channe } \\
\text { l/nursing-educat } \\
\text { ion-in-video?q=i } \\
\text { ntracranial) }\end{array}$ & $\begin{array}{l}\text { Cranial Nerves } \\
\text { (https://www-jov } \\
\text { e-com.proxyiub. } \\
\text { uits.iu.edu/sear } \\
\text { ch?q=intracrani } \\
\text { al\&exclude_sec } \\
\text { tions }=15+48+1 \\
1+0+49+13+29 \\
i+12+14+47+2+ \\
4+1+50+112)\end{array}$ \\
\hline
\end{tabular}

Table 3

Similar Topics Between the ACRL Standards and the AACN Essentials

\begin{tabular}{|c|c|c|c|c|}
\hline $\begin{array}{l}\text { Citations from Literature } \\
\text { Review, References to ACRL } \\
\text { Standards and Essentials }\end{array}$ & Visual Communication & Observation skills & Critical Thinking & Data Literacy \\
\hline $\begin{array}{l}\text { ACRL Visual Literacy Competency } \\
\text { Standards } 2011\end{array}$ & $\begin{array}{l}\text { Standard 3: } \\
\text { Performance indicator 1, } \\
\text { Learning outcomes A., B., C. } \\
\text { Performance indicator 2, } \\
\text { Learning outcomes B., C., E. } \\
\text { Performance indicator 3, } \\
\text { Learning outcomes A., B. } \\
\text { Performance indicator 4, All } \\
\text { learning outcomes } \\
\text { Standard 5: } \\
\text { Performance indicator 1, } \\
\text { All learning outcomes } \\
\text { Standard 6: } \\
\text { Performance indicator 1, } \\
\text { All learning outcomes } \\
\text { Performance indicator 3, } \\
\text { Learning outcome C. } \\
\text { Performance indicator 4, } \\
\text { All learning outcomes. }\end{array}$ & $\begin{array}{l}\text { Standard 3: } \\
\text { All performance indicators, } \\
\text { All learning outcomes. } \\
\text { Standard 4: } \\
\text { All performance indicators, } \\
\text { All learning outcomes. }\end{array}$ & $\begin{array}{l}\text { *It could be argued that all } \\
\text { of the } A C R L \text { Standards } \\
\text { include critical thinking. * }\end{array}$ & $\begin{array}{l}\text { Standard One: } \\
\text { Performance indicator 2, } \\
\text { Learning outcomes C., D. } \\
\text { Standard Four: } \\
\text { Performance indicator 1, } \\
\text { Learning outcomes D., F., G. } \\
\text { Standard Six: } \\
\text { Performance indicator 1, } \\
\text { All Learning outcomes. }\end{array}$ \\
\hline AACN Essentials 2008 & $\begin{array}{l}\text { Essential II: } \\
\text { Performance indicators 3,4. } \\
\text { Essential IV: } \\
\text { Performance indicators } \\
1,2,6 \text {. }\end{array}$ & $\begin{array}{l}\text { Essential III: } \\
\text { Performance indicator } 6 \\
\text { Essential IV: } \\
\text { Performance Indicator } 12 \\
\text { Essential VI: } \\
\text { Performance indicator } 1 \\
\text { Essential VII: } \\
\text { Performance indicators } \\
\text { 1,2,8,9,13 } \\
\text { Essential IX: }\end{array}$ & $\begin{array}{l}\text { *It could be argued that all } \\
\text { of the } A A C N \text { Essentials } \\
\text { include critical thinking. }{ }^{*}\end{array}$ & $\begin{array}{l}\text { Essential IX: } \\
\text { Performance Indicator } 1 \\
\text { Essential IV: } \\
\text { Performance indicator 6,8 }\end{array}$ \\
\hline
\end{tabular}

While these skills are broad, the goal is to narrow them down through further revision. The terminology is meant to be somewhat general because the authors want nursing professors to be able to adapt the learning outcomes to their specific curriculum. As this table goes into revision and Fleming and Minix start writing learning outcomes, the authors hope to keep things somewhat broad for ease of use. One difficulty 
in organizing the competencies within the identified categories was the overly broad nature of the term critical thinking. Throughout the literature review, the term critical thinking is identified as an essential skill for nursing students numerous times. However, both authors agree that both sets of competencies can be argued to embrace critical thinking. Because of this, the authors decided to put the entire ACRL Standards and the AACN Essentials under the critical thinking category. This may take more thought and revision as the authors start writing out the learning outcomes in the near future.

\section{Next Steps}

Writing the learning outcomes has taken a bit longer than expected because the authors are still learning about the specifics of the nursing curriculum at their institution. However, before they speak with more nursing professors in their institutions School of Nursing, the authors want to have something concrete to show them. The authors plan to draft the learning outcomes and then consult the Teaching \& Learning department at their institution for feedback since writing learning outcomes is something they specialize in ${ }^{6}$. In addition to the learning outcomes, the authors hope to create a graphic with the general skills outlined in Table 3. This graphic will be inspired by the Visual Literacy Array (cite) graphic that is based on the ACRL Standards ${ }^{7}$. The purpose in creating this graphic is to have a clear and concise visual representation of how the learning outcomes can be incorporated into the current curriculum at the School of Nursing.

\section{Conclusion}

At the time of writing, it has been almost a year since COVID-19 began impacting the lives of millions and the structure of higher education. One of the most difficult aspects of this has been planning for the future when there is so much uncertainty. While we are still living in uncertain times, both authors feel that their work can positively impact the curriculum of the School of Nursing. If the pandemic has taught the world anything, it is that nurses and doctors are essential parts of society. They need to have a strong education that prepares them for anything in their future careers. The authors strongly believe that having a visual literacy skill set is a part of that preparation.

\section{References}

American Association of Colleges of Nursing. (2008) The essentials of baccalaureate education for professional nursing practice. Washington, D.C.: American Association of Colleges of Nursing.

Association of College \& Research Libraries. (2011, October). ACRL visual literacy competency standards for higher education. http://www.ala.org/acrl/standards/visualliteracy

Brown, N.E., Bussert, K., Hatwig, D., \& Medaille, A. (2013, October 21). Keeping Up With... Visual Literacy. Association of College \& Research Libraries (ACRL). http://www.ala.org/acrl/publications/keeping up with/visual literacy

Choi, H., Lee, U., Jeon, Y. S., \& Kim, C. (2020). Efficacy of the computer simulation-based, interactive communication education program for nursing students. Nurse Education Today, 91, 104467. https://doi.org/10.1016/..nedt.2020.104467

Coyne, E. (2021). A review of virtual-simulation for assessing healthcare students' clinical competency. Nurse Education Today, 96, 1-10. https://doi.org/10.1016/j.nedt.2020.104623

Coyne, E., Frommolt, V., Rands, H., Kain, V., \& Mitchell, M. (2018). Simulation videos presented in a blended learning platform to improve Australian nursing students' knowledge of family assessment. Nurse Education Today, 66, 96-102. https://doi.org/10.1016/i.nedt.2018.04.012

Dubovi, I. (2018). Designing for online computer-based clinical simulations: Evaluation of instructional approaches. Nurse Education Today, 69, 67-73. https://doi.org/10.1016/j.nedt.2018.07.001

Gandhi, S., Yeager, J., \& Glaman, R. (2020). Implementation and evaluation of a pandemic simulation 
exercise among undergraduate public health and nursing students: A mixed-methods study. Nurse Education Today, 104654. https://doi.org/10.1016/j.nedt.2020.104654

Granheim, B. M., Shaw, J. M., \& Mansah, M. (2018). The use of interprofessional learning and simulation in undergraduate nursing programs to address interprofessional communication and collaboration: An integrative review of the literature. Nurse Education Today, 62, 118-127. https://doi.org/10.1016/j.nedt.2017.12.021

Housen, A. (2002). Aesthetic thought, critical thinking, and transfer. Arts and Learning Research Journal, 18(1), 99-131.

Hsieh, P.-Y., Lin, H.-Y., Chang, C.-H., Chang, Y.-C., Cheng, H.-P., Wang, C.-Y., Wang, M.-L., Wang, H.J., Liu, H.-T., Chen, J.-S., \& Hsiao, F.-H. (2020). Effects of Situational Simulation and Online First-Aid Training Programs for Nurses in General Medical Wards: A Prospective Study. Nurse Education Today, 104621. https://doi.org/10.1016/j.nedt.2020.104621

Jasani, S. K., \& Saks, N. S. (2013). Utilizing visual art to enhance the clinical observation skills of medical students. Medical Teacher, 35(7), e1327-e1331. https://doi.org/10.3109/0142159X.2013.770131

Kim, S., Park, C., \& O'Rourke, J. (2017). Effectiveness of online simulation training: Measuring faculty knowledge, perceptions, and intention to adopt. Nurse Education Today, 51, 102-107. https://doi.org/10.1016/j.nedt.2016.12.022

Kostovich, C. T., O'Rourke, J., \& Stephen, L.-A. (2020). Establishing psychological safety in simulation: Faculty perceptions. Nurse Education Today, 91, 104468. https://doi.org/10.1016/j.nedt.2020.104468

Lee, N. (2020). Using simulation to teach undergraduate nursing and midwifery students research design. Nurse Education in Practice, 5.

Mackay, B. J., Anderson, J., \& Harding, T. (2017). Mobile technology in clinical teaching. Nurse Education in Practice, 22, 1-6. https://doi.org/10.1016/..nepr.2016.11.001

Mano, L. Y. (2019). Using emotion recognition to assess simulation-based learning. Nurse Education in Practice, 7.

Moorman, M., Hensel, D., Decker, K. A., \& Busby, K. (2017). Learning outcomes with visual thinking strategies in nursing education. Nurse Education Today, 51, 127-129. https://doi.org/10.1016/j.nedt.2016.08.020

Nadeau, C., Snowden, K., Gattamorta, K. A., \& Foronda, C. L. (2020). Use of simulation for global health pre-departure training. Nurse Education Today, 95, 104597. https://doi.org/10.1016/j.nedt.2020.104597

O'Flaherty, J., \& Costabile, M. (2020). Using a science simulation-based learning tool to develop students' active learning, self-confidence and critical thinking in academic writing. Nurse Education in Practice, 47, 102839. https://doi.org/10.1016/j.nepr.2020.102839

Ortega-Morán, J.-F., Pagador, B., Maestre-Antequera, J., Arco, A., Monteiro, F., \& Sánchez-Margallo, F. M. (2020). Validation of the online theoretical module of a minimally invasive surgery blended learning course for nurses: A quantitative research study. Nurse Education Today, 89, 104406. https://doi.org/10.1016/j.nedt.2020.104406

Shapiro, J., Rucker, L., \& Beck, J. (2006). Training the clinical eye and mind: Using the arts to develop medical students' observational and pattern recognition skills. Medical Education, 40(3), 263-268. https://doi.org/10.1111/j.1365-2929.2006.02389.x 
Terry, V. R., Terry, P. C., Moloney, C., \& Bowtell, L. (2018). Face-to-face instruction combined with online resources improves retention of clinical skills among undergraduate nursing students. Nurse Education Today, 61, 15-19. https://doi.org/10.1016/j.nedt.2017.10.014

Uslu-Sahan, F., \& Terzioglu, F. (2020). Interprofessional simulation-based training in gynecologic oncology palliative care for students in the healthcare profession: A comparative randomized controlled trial. Nurse Education Today, 95, 104588. https://doi.org/10.1016/j.nedt.2020.104588

\section{Footnotes}

${ }^{1}$ For more information about the Inter-Professional Simulation Center and the Nursing Learning Center, visit the School of Nursing website at the following link:

https://nursing.indiana.edu/undergraduate/interactive-learning-facilities/index.html.

${ }^{2}$ The Visual Thinking Strategies organization has a detailed website that explains the research behind the VTS method and how to become a certified VTS facilitator. https://vtshome.org/.

${ }^{3}$ There have been many partnerships between an institution's medical schools and the art museums on their campus. All of the case studies listed in the references of this article are examples of this. To see more examples of medical school and art museum partnerships, visit:

https://www.utdallas.edu/arthistory/medicine/resources/.

${ }^{4}$ To see the PowerPoint presentation the authors gave at the virtual IVLA conference, please email one of the authors, Jackie Fleming jkflemin@iu.edu or Minix, Amy Minix, alminix@iu.edu.

${ }^{5}$ To see the Excel Spreadsheet the authors shared with Dr. Barnes, email the authors

${ }^{6}$ The Teaching and Learning Center specializes in a variety of instructional techniques. For more information, visit their department website: https://libraries.indiana.edu/teaching-learning.

${ }^{7}$ The Visual Literacy Array Chart has appeared in a few publications including Keeping up with Visual Literacy and Portal: Libraries and the Academy journal.

\section{APA citation format $\left(7^{\text {th }}\right.$ edition) for this publication:}

Fleming, J. \& Minix, A. (2021). Supporting Visual Literacy in Nursing. In J. Lee, S. M. Christensen, $\mathrm{S}$. Beene, X. Chen, and W. Huang (Eds.), Visual literacy in the virtual realm: The book of selected readings 2021 (pp. 20-29). International Visual Literacy Association.

https://doi.org/10.52917/ivlatbsr.2021.013 